DOI: 10.12731/2227-930X-2019-1-26-49

УДК 656.628

\title{
ИСПОЛЬЗОВАНИЕ ТРЕХМЕРНЫХ НАВИГАЦИОННЫХ КАРТ ДЛЯ ПОВЫШЕНИЯ БЕЗОПАСНОСТИ СУДОВОЖДЕНИЯ ПО ВНУТРЕННИМ ВОДНЫМ ПУТЯМ
}

\section{Прохоренков А.А.}

Проводка судна по внутренним водным путям всегда представляла собой сложную задачу, требующую от судоводителя хороших знаний специальной лочии района плавания. Для уверенного ориентирования судоводитель должен правильно опознавать знаки навигащионного оборудования и ориентируясь по изменениям положения судна относительно них определять правильность движения судна и выполнять действия для его корректировки. Для надежности ориентирования судоводитель периодически обращается к навигаџионной информации, приведенной на картах атласов.

Навигационная информация для судоводителей традиционно представлялась в форме карт, которые вне зависимости от носителя, представляли плоскую модель местности. Двухмерные карты применяются до сих пор и служат множеству иелей, но они неизменно ограничивают восприятие.

В настоящее время пока только для иелей морского судоходства в стесненных условиях разработаны и внедряются трехмерныле картыл. Способ представления картографической информации в трех измерениях не является принципиально новым, однако для иелей судоходства стал применяться только в последнее десятилетие. В настоящей статье рассматриваются перспективы применения трехмерных навигационных карт для судоходства по внутренним водным путям.

Цель - идентификация новых особенностей управления судном с использованием трехмерных навигащионных карт для по- 
выления навигационной безопасности плавания по внутренним водным путям.

Метод или методология проведения работы: в статье использовались методы ситуационного и структурного анализа качественно-сложной организационно-технической системь судовождения.

Результаты: проведен сравнительный ситуационный анализ использования трехмерных навигационных карт применительно к особенностям условий плавания на внутренних водных путях.

Область применения результатов: полученные результаты могут быть использованы при управление судами, оснащенными картографическими системами, отображающими трехмерные навигационные карты внутренних водных путей.

Ключевые слова: управление судном; навигационная безопасность плавания судов; электронные трехмерные навигационные карты; виртуальная реальность; визуальное ориентирование при управлении судном.

\section{USE OF THREE-DIMENSIONAL NAVIGATION CHARTS TO IMPROVE INLAND WATERWAYS NAVIGATION SAFETY}

\section{Prokhorenkov A.A.}

Navigating a ship through inland waterways has always been a difficult task, requiring a good knowledge of pilotage. For confident orientation the navigator must correctly recognize the navigation equipment marks and, guided by changes in the vessel's position relative to them, determine the correctness of the vessel's movement and take actions to correct it. For reliable positioning, the navigator periodically refers to the navigational information shown on navigation charts from atlas.

Navigation information for navigators has traditionally been presented in the form of charts, which, regardless of the carrier, represented a flat terrain model. Two-dimensional maps are used so far and serve many purposes, but they invariably limit perception. 
Nowadays, but so far for the purposes of maritime navigation in narrows, three-dimensional charts have been developed and are being implemented. The way of presenting cartographic information in three dimensions is not fundamentally new, but for shipping purposes it has been used only in the last decade. This article discusses the prospects for the use of three-dimensional navigational charts for inland navigation.

Purpose identification of new particulars in ship handling using three-dimensional navigation charts to improve navigational safety on inland waterways.

Methodology the article used the methods of situational and structural analysis of a qualitatively complex organizational and technical navigation system.

Results: a comparative situational analysis of the use of three-dimensional navigation charts was carried out in relation to the characteristics of navigation conditions on inland waterways.

Practical implications the results obtained can be used in the ship handling of vessels equipped with cartographic systems that display three-dimensional navigation charts on inland waterways.

Keywords: ship handling; navigational safety; electronic three-dimensional navigational charts; virtual reality; visual positioning in ship handling.

\section{Введение}

Традиционно навигационная информация для судоводителей представлялась в форме карт, которые вне зависимости от носителя, представляли участок водного пути на плоскости. Двухмерные карты служили и до сих пор служат множеству целей, но они неизменно ограничивают восприятие пользователя до двух измерений.

Необходимость применения трехмерных карт для целей судовождения возникла достаточно давно и многократно подтверждалась практикой. На картах наиболее затруднительных участков внутренних водных путей для информации судоводителям помещались фотографические изображения этих участков, сделанные с высоты и при хорошей видимости. Такие изображения пред- 
ставляли практический интерес для судоводителя, управляющего судном при проводке по незнакомому участку или при принятии решения в условиях интенсивного судоходства и необходимости оценить положение судна визуально. Такие изображения существенно дополняют информацию, получаемую судоводителем при обращении к навигационной карте. Но эти изображения были и являются статичными, их нельзя использовать напрямую для измерения или анализа, они представляют собой не источники информации, а, скорее, дополнения.

\section{Развитие и возможности трехмерной картографии}

Современные технологии позволяют создавать трехмерные карты, которые могут использоваться для проводки судов через узкости, но к сожалению, пока доступны только для морских районов и используются лоцманами и операторами систем управления движением судов $[10,19]$. Однако, информация о данных видах карт [15-18] позволяет сделать вывод о том, что за счет новых возможностей они также имеют большой потенциал для повышения навигационной безопасности плавания судов по внутренним водным путям.

Имеющиеся в настоящее время технологии создания цифровых трехмерных моделей позволяют максимально реалистично передавать геометрические характеристики исходного рельефа местности, искусственно созданных объектов, объектов векторной, растровой или матричной карты [7].

Для построения трехмерной модели местности могут использоваться: векторная карта, матрица высот, триангуляционная модель рельефа, классификатор карты, библиотека трехмерных изображений объектов, цифровые фотоснимки местности и цифровые панорамные фотографии местности или отдельных объектов [6]. Состав исходных данных может быть разным и зависит от требований к модели.

Модель, представляющая собой единую электронную базу данных может совмещать множество информационных источников, 
что значительно упрощает сопоставление самой различной, как правило, разрозненной информации [3,2].

Она является полноценной трехмерной картой, которая позволяет выбирать объекты на модели с целью запроса требуемой информации об объекте [5].

Трехмерное изображение дает возможность визуального пространственного анализа объектов, расположенных на разных уровнях над или под поверхностью земли [6], т.е. применительно к целям судовождения на трехмерной модели можно увидеть, как надводные, так и подводные объекты.

Применение стереоскопической визуализации, когда синтезируются два изображения с двух виртуальных камер, одно изображение - для левого глаза, другое - для правого, что обеспечивает восприятие формы, размеров и расстояний до объектов [1].

Применения мультимедийных средств и технологий существенно расширяет возможности отображения анимационной информации, к которой относятся [4]:

- динамика изменения местности в целом и отдельных пространственных объектов (явлений, процессов) и их характеристик;

- масштаб времени изображения (или временной масштаб изображения), то есть в картографические объекты добавляется еще одна координата - время, которой также можно управлять, переходить к определенному временному значению или интервалу, изменять скорость изменения (течения) времени;

- динамическая генерализация, которая отвечает за переход от картографического изображения одного временного состояния к другому, позднее или раньше по времени.

Динамическая генерализация выполняет настройку таких параметров как: скорость изменения характеристик объекта (явления, процесса); важность объектов (явлений); отслеживание изменения объекта (явления, процесса) во времени; взаимная согласованность на отдельном промежутке времени (более высокая сложность топологических связей). 
Необходимость совершенствования картографического обеспечения для повышения навигационной безопасности плавания $[8,9]$, а также способы достижения этой цели $[5,11-14]$, широко освещены как отечественными, так и иностранными учеными. Наглядность, трехмерных карт обусловили рост их применения не только специалистами, но и разностороннее практическое использование обычными пользователями. Анализ информации, посвященной функциональным возможностям трехмерных карт [11-14], позволяет сделать вывод о том, что количество задач, качество выполнения которых можно повысить при их использовании, значительно больше, чем предполагалось первоначально.

\section{Представление надводной обстановки}

Трехмерные карты, представляя навигационную обстановку в виртуальном пространстве, позволяют производить ее глазомерную оценку и анализ. Под надводной обстановкой применительно к судовождению понимается совокупность стационарных и плавучих знаков навигационного оборудования.

Правило, широко применяемое судоводителями при управлении судном в стесненных условиях, заключается в том, что надежными знаками для ориентирования можно считать только береговые знаки. На практике наблюдение береговых знаков не всегда беспрепятственно обеспечивается, например, при интенсивном судоходстве. При несоблюдении непрерывности в наблюдении трехмерная карта помогает определить особенности расстановки знаков навигационного оборудования, оценить периоды, когда те или иные знаки будут визуально видимы.

Наиболее надежным считается ориентирование по стационарным знакам, поскольку вероятность их смещения с места установки сведена к минимуму. При этом проход судна вблизи стационарных знаков ввиду меняющихся глубин, сопряжен с опасностью касания судном грунта или посадкой на мель.

Ориентирование относительно стационарных знаков с применением трехмерной карты позволяет, производить визуальную 
оценку фактических навигационных параметров т.е. дистанций, направлений и пр. и оценивать тенденцию их изменения и соответственно корректировать движение судна.

Ориентирование по плавучим знакам навигационного оборудования можно разделить на два этапа. Первое - определение нахождения знаков на штатных местах, для чего судоводитель должен оценивать расположение не отдельных знаков, а их совокупности. Второе - оценка местоположения и движения судна относительно совокупности знаков, наблюдаемых визуально.

При движении судна по дополнительным судовых ходам, обозначенным небольшим количеством плавучих знаков точность визуального ориентирования существенно снижается. Опознавание навигационных знаков на местности в этом случае представляет собой непростую задачу. Наличие небольшого количества знаков навигационного оборудования требует использования навигационных приборов для выполнения измерений в дополнение к визуальному ориентированию.

Опознав знаки визуально можно определить безопасный курс и периодически с использованием приборов оценивать смещение судна в направлении левого или правого борта. Поскольку знаки находятся на определенном расстоянии, то для понимания того приближается ли судно к знаку или удаляется необходимо оценивать движение судна в направлении траверза.

На дополнительных судовых ходах плавучими знаками обозначается только одна из кромок судового хода, что также влияет на точность определения места судна поскольку определение направления движения осуществляется сравнением изменения положения навигационных знаков с обоих бортов.

При движении в таких навигационных условиях усложняется оценка границ навигационных опасностей. Использование трехмерных карт, как дополнительного источника визуальной информации, позволяет однозначно решить эту проблему и визуально оценить область, безопасную для движения судна.

При прохождении участков со значительными изменениями направления движения, необходимость своевременно и точно ме- 
нять курс. Угловая скорость в процессе изменения курса может достигать больших значений, при этом может быть затруднительно оценивать дистанции до ближайших опасностей и ориентироваться на перспективу. Быстрое развитие ситуации может привести к неверному решению по управлению судном, особенно у судов с плохими маневренными качествами или при значительных гидрометеорологических воздействиях.

Использование трехмерной карты в этом случае может повысить точность контроля за местоположением и параметрами движения судна при подходе к точке начала поворота, криволинейного движения судна и выхода в точку окончания поворота.

Одной из главных задач судоводителя является ведение непрерывного визуального наблюдения, которое дает основную информацию, необходимую для принятия решений. Однако, в ночных условиях и при плохой видимости, количество получаемой с помощью визуального наблюдения информации значительно уменьшается, так как исчезают очертание берега, судов и объектов. В результате усложняется оценка обстановки, становиться труднее принимать решения.

Настройка картографического изображения применительно к условиям ограниченной видимости или видимости в ночное время суток повышает быстроту визуального ориентирования, позволяет избежать грубых промахов и просчетов.

\section{Представление подводной обстановки}

На внутренних водных путях движение судов возможно по судовому ходу - части водного пространства, предназначенной для движения судов и обозначенной на местности и/или на карте. Навигационные условия на внутренних водных путях характеризуются ограниченными габаритами судового хода, наличием большого количества навигационных опасностей, расположенных как вблизи кромок судового хода, так и в его пределах, извилистостью судового хода.

При проводке судна по внутренним водным путям работа судоводителя заключается в постоянной оценке положения судна и его движения относительно направлений и границ судового хода, 
выполнении действий для корректирования этого движения таким образом, чтобы траектория движения судна была кратчайшей и проходила на безопасной дистанции от навигационных опасностей, а скорость была наибольшей.

Ориентирование при проводке судна, как правило, осуществляется визуально, с учетом знаний особенностей местных условий плавания т.е. лоцманским методом.

Для надежного ориентирования судоводитель в процессе проводки судна периодически обращается к навигационной карте, для уточнения положения знаков навигационного оборудования, параметров судового хода, расположения навигационных опасностей. Таким образом, качество навигационной информации, которую возможно получить, используя ту или иную навигационную карту, будет иметь определяющее значение для безопасности проводки судна.

Под качеством навигационных карт понимается совокупность свойств, обеспечивающих способность карты удовлетворять целям судовождения. Качество карты оценивается набором показателей, характеризующих отдельные ее свойства: полноту, достоверность, современность, точность, наглядность изображения и др.

Карта представляет собой определенную модель того участка земной поверхности для которого она выполнена, с некоторой требуемой точностью. Основное назначение карты - графическое определение положения наблюдателя на местности, поэтому точность карты является одним из основных критериев, наиболее ценных для оценки возможностей карты для ориентирования и определения места наблюдателя.

Точность карт может быть определена как соответствие позиций изображенных на карте объектов и явлений действительности, т.е. как истинность местоположения, размеров, плановых очертаний и высот объектов. Однако не следует забывать о том, что несмотря даже на наличие точных данных для создания карты, представить ее в виде удобном для практического применения может быть затруднительно. Это связано в первую очередь с ограниченными возможностями представления информации на двухмерной карте (рис. 1). 


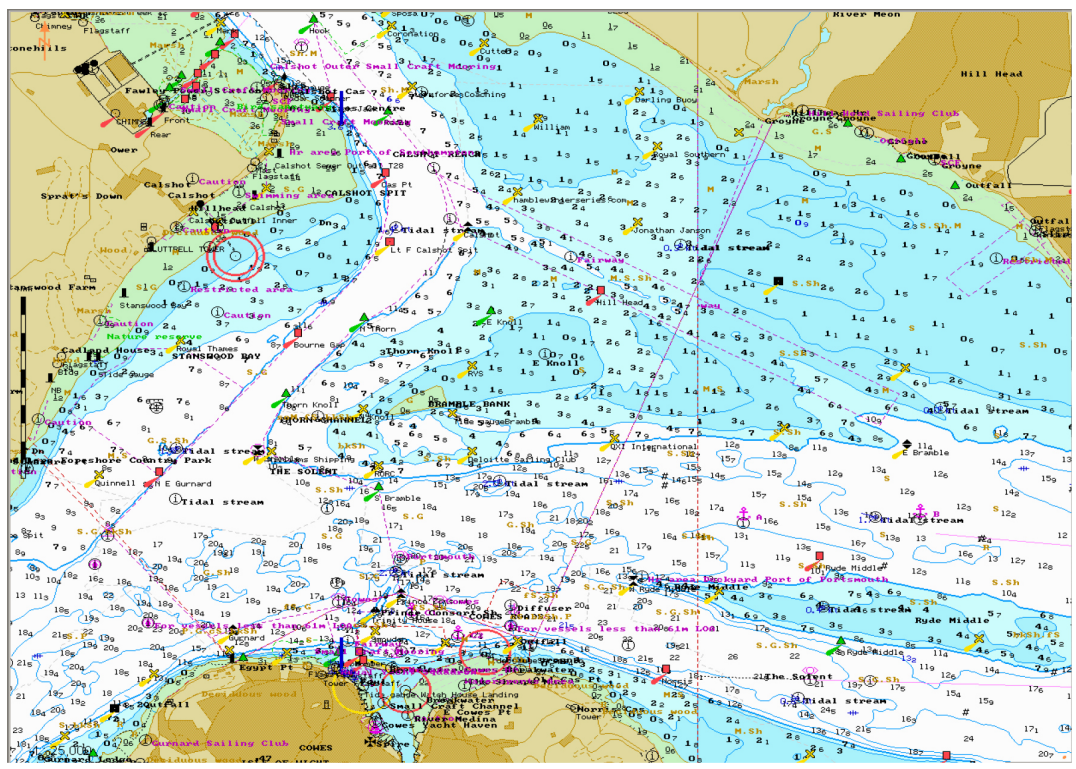

Рис. 1. Фрагмент электронной карты подходного фарватера порта Саутгемптон

Точность и полнота информации о глубинах, отображаемой на карте будет иметь определяющее значение на восприятие подводной обстановки судоводителем. К настоящему времени, электронные карты, выполненные в полном соответствие со всеми международными стандартами, представляют собой копии бумажных карт.

Несмотря на большие возможности по настройке отображения навигационной информации, применительно к гидрометеорологическим навигационно-гидрографическим и иным особенностям конкретного района [20], для обеспечения безопасности судна при его проводке судоводителю всегда приходится учитывать дискретность представленной информации о глубинах. На картах отображаются отличительные глубины т.е. находящиеся в определенном диапазоне относительно окружающих. Такой принцип нанесения глубин позволяет избежать информационной перегрузки карты и упростить работу судоводителя по определению безопасного пути судна. 
Дискретность нанесения глубин влияет на полноту представления судоводителя о рельефе дна и кромок фарватера особенности которого оказывают влияние на инерционные характеристики судна, его управляемость, а также определяют рыскливость судна, вызванную гидродинамическим взаимодействием с корпусом судна при его движении.

Для оценки особенностей гидродинамических явлений при движении также необходимо учитывать сезонные и периодические колебания уровня воды, которые можно получить расчетным путем по стандартным методикам.

Проводка судна по участкам, глубины на которых подвержены изменениям, предполагает расчет фактического уровня воды на период проводки судна и установки значения опасной изобаты. Однако дискретность нанесения изобат на карту редко будет позволять выбрать отображение той изобаты, которая необходима для конкретного судна с конкретной осадкой. Поэтому судоводителю приходится выбирать значение безопасной изобаты, отличающееся от расчетного значения, а фактическое положение действительной опасной изобаты оценивать при помощи измерений по приборам или глазомерно.

Просмотр трехмерной карты в крупном масштабе вблизи судна не влечет за собой уменьшение количества информации, наблюдаемой в перспективе, эта информация лишь генерализируется, но остается по прежнему видимой.

В процессе масштабирования карты изменение глубин в интересующем судоводителя районе, отображается не скачкообразно, а плавно, за счет использования градиентного заполнения, вместо отображения численных значений.

Отсутствие стыков, также способствует целостности восприятия глубин, поскольку их наличие при наложении карт разной точности может приводить к неоднозначности отображения информации о глубинах.

При просмотре карты и одновременном масштабировании не возникает перегруженности зрительного восприятия подводного 
рельефа, поскольку глубины обозначаются не численными значениями, каждое из которых необходимо просмотреть и оценить, а областями, имеющими непрерывное цветовое заполнение. Эффективность такого решения наглядно демонстрирует рисунок 2 , на котором представлены фрагменты трехмерной карты района подхода к порту Саутгемптон при масштабировании.

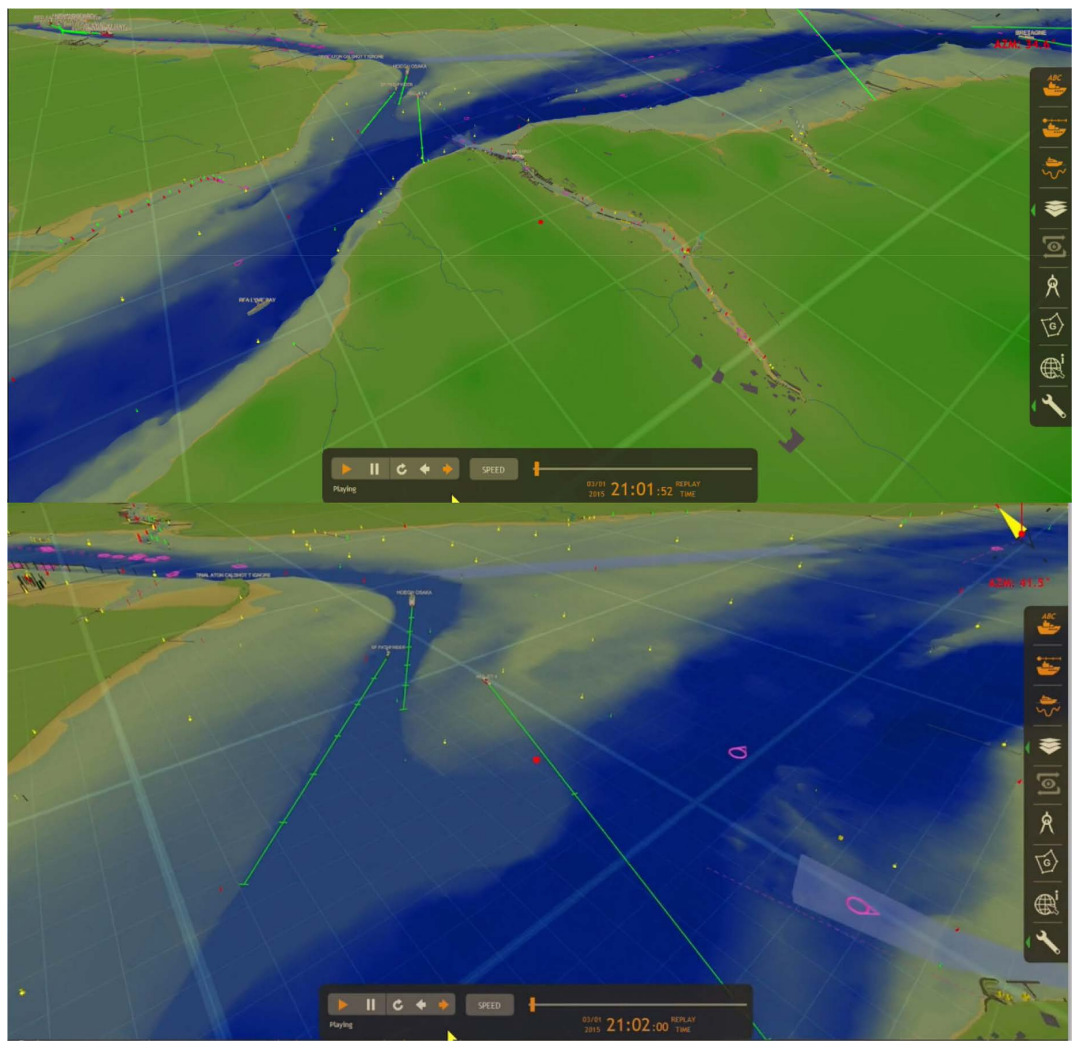

Рис. 2. Фрагменты электронной трехмерной карты района подхода к порту Саутгемптон при масштабировании

Сравнивая отображение глубин при мелком и более крупном масштабе, можно отметить соответствие их представления последовательности задач, решаемых судоводителем, когда отображе- 
ние глубин на удалении, пропорциональном линейным размерам судна, значимо в краткосрочной перспективе. Информация на долгосрочную перспективу пропорционально удалению от точки просмотра каты генерализируется, объединяя области отличных друг от друга глубин и, обеспечивая читаемость карты.

Наличие вспомогательных линий параллелей и меридианов, которые несмотря на достаточную плотность не перегружают карту и позволяет оценивать тенденции перемещения судна не только согласно вектору скорости, но и глазомерно, при этом отсутствует необходимость инструментальной прокладки дополнительных линий.

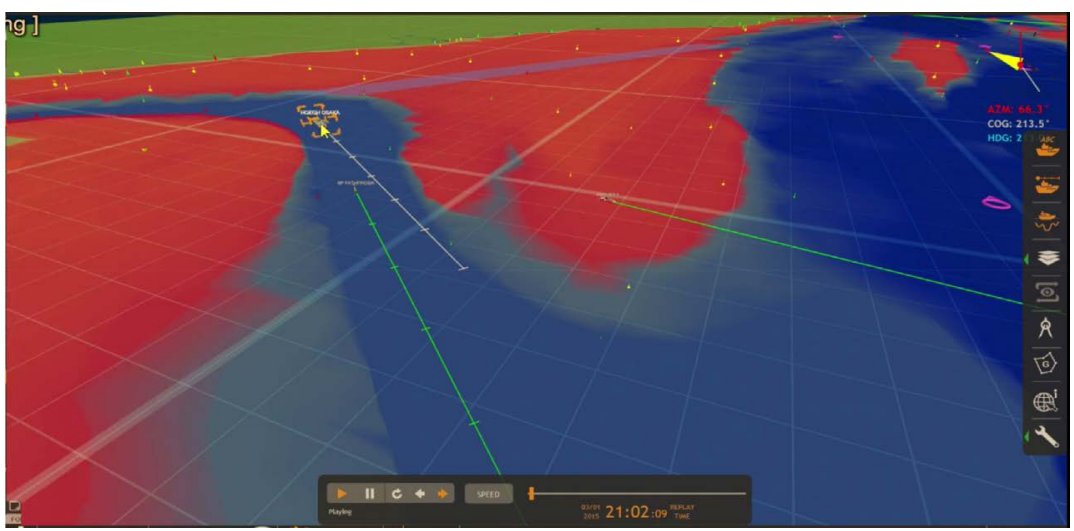

Рис. 3. Отображение области опасных глубин применительно к осадке выбранного судна

Функционирование трехмерных карт требует информации высокой точности и дискретности, получение такой информации возможно на основание точных измерений, которые могут быть выполнены при наличии соответствующего оборудования. В то время как для работы стандартных навигационных электронных карт такой точности не требуется, однако информация о точности промеров помещается на карту, что позволяет судоводителям прокладывать путь судна на достаточном удалении от навигационных опасностей при учете запасов к кратчайшей дистанции в связи с различными погрешностями. 
Если осадка судна позволяет следовать за кромками судового хода, то полностью отпадает или снижается до минимума возможность ориентирования по плавучим знакам, поскольку кромка находится со стороны одного борта, а определение безопасного направления движения осуществляется сравнением изменения положения навигационных знаков с обоих бортов.

При движении за кромками судового хода расположение навигационных опасностей может быть нечетко выражено, т.е. встречаются отдельные глубины, которые близки к предельным, а окружающие глубины достаточные. Применение трехмерных карт при ориентировании позволяет однозначно решить эту проблему и выделить область, безопасную для движения судна.

Для оперативности оценки имеющегося водного пространства применительно к осадке судна и состоянию уровня воды в трехмерных картах предусмотрена функция автоматического перестроения, разбивающая водное пространство, охватываемое картой на области опасных и безопасных глубин рис.3.

\section{Оценка оперативности получения навигационной информации при использовании трехмерных карт}

Управление судном на внутренних водных путях представляет собой непрерывный процесс по оценке и корректировке положения и движения судна, относительно совокупности плавучих и стационарных знаков навигационного оборудования, наблюдаемых с ходового мостика. Для опознания знаков навигационного оборудования судоводитель периодически обращается к навигационной карте, уточняя положение знаков визуально или при помощи инструментальных измерений. Опознав знаки навигационного оборудования, судоводитель может произвести оценку местоположения судна. Полнота оценки надводной и подводной навигационной обстановки, которой удается достигнуть за счет навигационной карты, будет определять количество и продолжительность периодов обращений судоводителя за навигационной информацией на навигационную карту. 
Таким образом за время, затраченное на работу с навигационной картой судно будет проходить определенное расстояние по лини пути, и, также смещаться в перпендикулярном направление. Поэтому для случая использования точных измерений всегда будет присутствовать ошибка, связанная с перемещением судна за время выполнения самих измерений и их обработки.

Период отображения панелей меню устанавливается пользователем применительно к особенностям выполняемой задачи, что позволяет отображать их только при работе курсором в определенной области просмотра карты. Таким образом, обязательных периодических действий оператора для просмотра соответствующих областей карты не требуется.

Изменение ориентации карты происходит плавно за счет вращения колеса трехмерной мыши с возможностью одновременной подачи команд для масштабирования и изменения положения точки обзора.

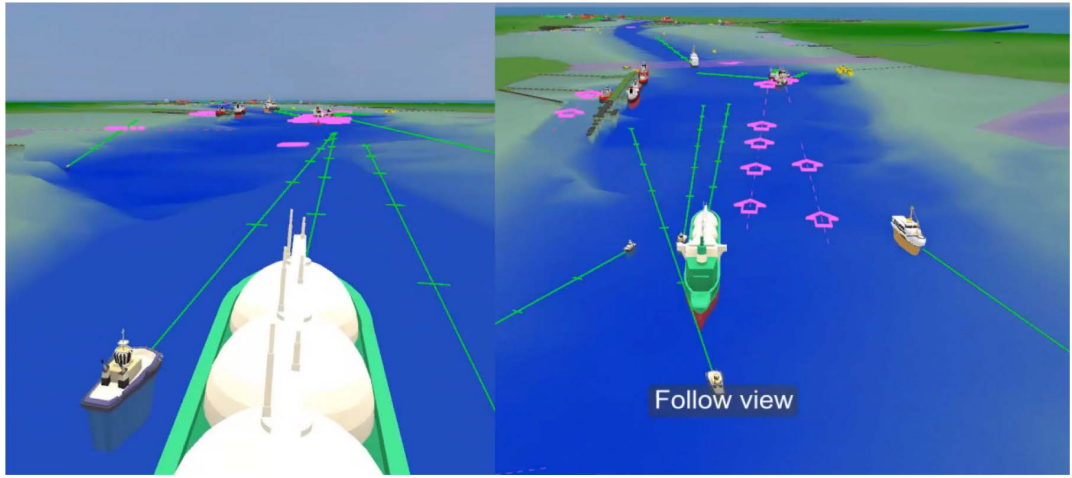

Рис. 4. Положение собственного судна, отображаемое на трехмерной карте:

а) вид с мостика; б) вид с точки, расположенной вне судна

Запрашиваемые пользователем окна, содержащие данные о параметрах движения судна не закрывают навигационную картографическую информацию. Имеются такие важные функции как наложение радиолокационного изображения, запись траектории движения с возможностью визуального отображения. 
Управление трехмерной картой (рис.4) позволяет судоводителю как устанавливать настройки, изменяющие количество отображаемой навигационной информации, и таким образом упрощающие восприятие навигационной ситуации, складывающейся вокруг судна, так и оценивать положение судна с различных ракурсов, изменяя положение точки обзора. Изменение положения точки обзора дает судоводителю возможность визуально оценивать дистанции и направления на отдельные навигационные ориентиры либо на несколько ориентиров одновременно, что невозможно на стандартной навигационной электронной карте.

Работа с трехмерными картами позволяет уменьшить временные затраты на получение навигационной информации за счет использования режима просмотра карты с мостика виртуального судна управления перемещением по карте трехмерной мышью. Для судоводителя при проводке судна по внутренним водным путям необходимо иметь представление о направлениях, создаваемых знаками навигационного оборудования и в первую очередь берегового. Поля навигационных параметров, создаваемые плавучими знаками навигационного оборудования, можно использовать для определения местоположения судна с высокой точностью, только при наличие хороших знаний специальной лоции. Т.е. при безошибочном опознании некоторой совокупности плавучих знаков навигационного оборудования, и их непрерывном наблюдении. Использование трехмерных карт позволяет судоводителю, не тратить время на отдельные инструментальные измерения, делать это визуально т.е. «на глаз». Можно достигать высокой точности глазомерных измерений за счет перемещения по трехмерной карте и выборе углов обзора, обеспечивающих максимальную точность. Точное наблюдение за изменением положения судна относительно знаков плавучего навигационного оборудования без дополнительных временных затрат на инструментальные измерения также предупреждают судоводителя от совершения грубого промаха.

Пример навигационной обстановки, наблюдаемой с мостика виртуального судна представлен на рисунке 5. Сопоставление дан- 
ных о параметрах движения судна, отображаемых на трехмерной карте, с реальным движением судна при проводке, также не требует длительного переключения внимания, дает возможность выполнять оценку экстраполяции не по совокупности последовательных наблюдений за изменением положения судна, а на основании измерений.

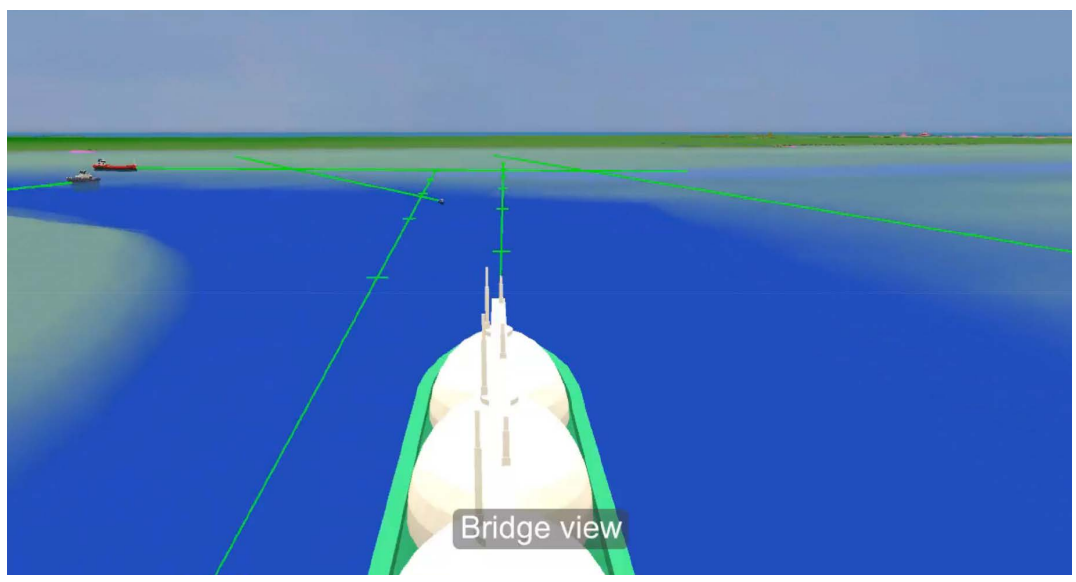

Рис. 5. Вид с мостика собственного судна на трехмерной карте при подходе к точке начала поворота

При высокой точности измерений, например, использовании приемоиндикаторов спутниковых навигационных систем, работающих в дифференциальном режиме, можно существенно снизить ошибки маневрирования, вызванные инерцией судна.

\section{Выводы}

В результате проделанного анализа функциональности, принципов работы, перспектив использования трехмерных карт выявлены следующие преимущества их применения в процессе несения ходовой вахты при проводке судна по внутренним водным путям:

- возможность регулировать точку обзора позволяет повысить скорость полноту оценки местоположения и движения судна относительно навигационных опасностей, а также визуаль- 
ную оценку частных навигационных параметров, например, направлений и дистанций до ближайших навигационных опасностей;

- возможность регулировать высоту глаза наблюдателя позволяет повысить полноту контроля за движением судна относительно знаков навигационного оборудования;

- снижение информационной нагрузки, при визуальной оценке подводной обстановки вблизи судна позволяет повысить внимание на положении и перемещении других судов.

Основным достоинством трехмерного отображения данных является возможность представления важных элементов навигационной обстановки в виде удобном для восприятия и анализа человеком, и более полного ее анализа при плавании в стесненных водах, интенсивном судоходстве, особенно в ночных условиях и при ограниченной видимости. Оказывает помощь трехмерная модель подводной обстановки и при плавании на мелководье со сложным рельефом дна.

Трехмерные навигационные карты позволяют объединять процесс определения места судна и нанесения его на карту, что позволило производить обсервации и отображать положение судна на электронной карте в реальном времени практически непрерывно, с интервалом в одну секунду и даже чаще. Они отображают цифровые данные о курсе, скорости, глубине под килем, и другие параметры движения судна на одном экране, избавляя судоводителя от необходимости обращения ко многим приборам.

Использование трехмерных электронных навигационных карт, снижает неопределенность при судовождении, позволяя судоводителю перераспределять внимание, концентрировать внимание на ключевых вахтенный помощник освобождается от выполнения многих рутинных операций. Его основными функциями становится наблюдение за окружающей обстановкой, контроль других средств судовождения, управление их работой для получения требуемых обстановкой сведений, оценка предоставляемой информации и принятие решений по управлению судном.

Внедрение трехмерных электронных навигационных карт позволит повысить результативность деятельности судоводителя, за 
счет представления навигационной информации в удобном виде для восприятия и анализа, увеличивает скорость их обработки, улучшает точность и достоверность результатов их оценки судоводителем, упрощает оценку навигационной ситуации повышает безопасность судовождения на внутренних водных путях.

\section{Список литературы}

1. Бобков A.Е. Интерактивная визуализация 3D-данных на виртуальном глобусе в стереоскопических системах: дис. ... к-та технических наук, Нижний Новгород, 2013. URL: http://tekhnosfera. com/interaktivnaya-vizualizatsiya-3d-dannyh-na-virtualnom-globusev-stereoskopicheskih-sistemah (дата обращения 04.02.2019).

2. Кацко С.Ю. Неогеография и картография // Интерэкспо Гео-Сибирь-2013. IX Междунар. науч. конгр., 15-26 апреля 2013 г., Новосибирск: Межд. науч. конф. «Геодезия, геоинформатика, картография, маркшейдерия»: сб. мат-в в 3т. Т. 2. Новосибирск: СГГА, 2013. С. 102-106.

3. Коростылев Р.И., Еремин И.Е. Электронная карта с использованием реалистичных 3D-моделей зданий // Ученые заметки ТОГУ. 2013. T. 4, № 3. C. 67-71. URL: http://pnu.edu.ru/media/ejournal/ articles/2013/TGU_4_24.pdf (дата обращения 04.01.2019).

4. Лисицкий Д.В., Комиссарова Е.В., Колесников А.А., Шарыпова М.Н. Анимационная картография - одно из перспективных направлений картографической науки и практики в современных условиях картографирования динамики процессов и явлений // Материалы Международной конференции «ИнтерКарто/ИнтерГИС». 2016. -№ 22 (1) C. 213-220. URL: https://doi.org/10.24057/24149179-2016-1-22-213-220 (дата обращения 04.02.2019).

5. Матерук А.У., Утробина Е.С. Некоторые вопросы становления навигационной картографии // Изв. Вузов «Геодезия и аэрофотосъемка». 2014. № 5. С. 43-47.

6. Степанова Л.А., Смирнова И.И. 3D-моделирование в геоинформационной системе // Программные продукты и системы. 2013, № 1. C. 122-125. 
7. Цветков В.Я. Цифровые карты и цифровые модели // Международный журнал прикладных и фундаментальных исследований. 2016. № 4-2. C. 348-351. URL: https://applied-research.ru/ru/article/ view?id=8969 (дата обращения: 20.02.2019).

8. Goralski, R., Ray, C. and Gold, C. Applications and benefits for the development of cartographic 3D visualization systems in support of maritime safety. TransNav-International Journal on Marine Navigation and Safety of Sea Transportation, 5, 2011, pp.423-431.

9. Haasea K., Kocha R. Extension of sea charts for 3-d visualization, 5th International 3D GeoInfo Conference, November 3-4, 2010, Berlin, Germany, pp. 125-128. URL: https://www.isprs.org/proceedings/XXXVIII/4-W15/Paper_ISPRS/Poster/9_3DGeoInfo2010_124_Haase_Extension_of_Seecharts.pdf (дата обращения 14.01.2019).

10. Hosgetts L. Poole Harbour's navigational safety goes 3D, February 28, 2013. URL: https://www.pbo.co.uk/news/poole-harbours-navigational-safety-goes-3d-3556 (дата обращения 04.02.2019).

11. Morgère, J.-C. Mobile augmented reality system for maritime navigation. Ph.D diss., Lorient, 2015 URL: http://www.theses.fr/2015LORIS365.pdf / (дата обращения 04.02.2019).

12. Porathe, T. Visualizing the Decision Space of a Ship's Maneuverability in a Real-Time 3-D Nautical Chart. In Visualisation and the Common Operational Picture, (pp. 23-1 - 23-10). Meeting Proceedings RTO-MP-IST-043, Paper 23. 2005, Neuilly-sur-Seine, France, RTO. URL: https://www.researchgate.net/publication/228730056_Visualizing_the_Decision_Space_of_a_Ship's_Maneuverability_in_a_Real-Time_3-D_Nautical_Chart (дата обращения 14.01.2019).

13. Porathe, T. 3-D nautical charts and safe navigation. Ph.D., Gävle, Sweden, 2006. URL: http://www.diva-portal.org/smash/get/diva2:120506/ FULLTEXT01.pdfAn (дата обращения 04.02.2019).

14. Ray C., Goralski R., Claramunt C. and Gold, C. Real-time 3D monitoring of marine navigation. Information Fusion and Geographic Information Systems, Published in: Lecture Notes in Geoinformation and Cartography, 2011, Berlin, 161-175.

15. C-Vu® 3D VTS - Milford Haven / demonstration video. URL: https:// vimeo.com/38025373 (дата обращения 07.11.2018). 
16. C-Vuß 3D VTS - Southampton / demonstration video. URL: https:// vimeo.com/45640579 (дата обращения 07.11.2018).

17. Demonstration of the GeoVS Maritime Domain Awareness (MDA) real-time 3D VTS display technology from SRT Marine System Solutions / demonstration video. URL: https://vimeo.com/101169448 (дата обращения 07.11.2018).

18. Pilotage out of Poole / demonstration video. https://vimeo.com/59227199 (дата обращения 07.11.2018).

19. New 3D vessel traffic management system enhances safety at Poole Harbour, February 25, 2013. URL: http://shipmanagementinternational.com/new-3d-vessel-traffic-management-system-enhances-safety-atpoole-harbour/ (дата обращения 7.11.2018).

20. Transas Marine, Navi - Sailor 4000 (ver. 6.42), Navigational Bridge, Transas Marine GB, Ltd., 2007.

\section{References}

1. Bobkov A.E. Interaktivnaya vizualizatsiya 3D-dannykh na virtual'nom globuse v stereoskopicheskikh sistemakh [Interactive visualization of 3D data on a virtual globe in stereoscopic systems]: Ph.D diss., Nizhny Novgorod, 2013. http://tekhnosfera.com/interaktivnaya-vizualizatsiya-3d-dannyh-na-virtualnom-globuse-v-stereoskopicheskih-sistemah (accessed February 4, 2019).

2. Katko S.Y. Neogeografiya i kartografiya [Neogeography and cartography]. Interekspo Geo-Sibir'-2013. IX Mezhdunar. nauch. kongr., April 15-26, 2013, Novosibirsk: Mezhdunar. nauch. konf. «Geodeziya, geoinformatika, kartografiya, marksheyderiya»: sb. materialov $\mathrm{v}$ 3t. T. 2. Novosibirsk: SGGA, 2013, pp.102-106.

3. Korostylyov R. I., Eremin I. E. Elektronnaya karta s ispol'zovaniyem realistichnykh 3D-modeley zdaniy [Electronic map using realistic 3D-models of buildings]. Uchenyye zametki TOGU, 2013, V. 4, no 3, pp. 67-71. http://pnu.edu.ru/media/ejournal/articles/2013/TGU_4_24. pdf (accessed January 4, 2019).

4. Lisitsky D.V., Komissarova E.V., Kolesnikov A.A., Sharypova M.N. Animatsionnaya kartografiya - odno iz perspektivnykh napravleniy 
kartograficheskoy nauki i praktiki $v$ sovremennykh usloviyakh kartografirovaniya dinamiki protsessov i yavleniy [Animation cartography - one of the perspective directions in cartographic science and practice in the current conditions of mapping the dynamics processes and effects]. Materialy Mezhdunarodnoy konferentsii «InterKarto/InterGIS», 2016, no. 22 (1) pp. 213-220. https://doi.org/10.24057/24149179-2016-1-22-213-220 (accessed January 4, 2019).

5. Materuk A.U., Utrobina E.S. Nekotoryye voprosy stanovleniya navigatsionnoy kartografii [Issues of formation of navigation cartography]. Izv. Vuzov, "Geodeziya i aerofotos'yemka», 2014, no. 5, pp. 43-47.

6. Stepanova L.A., Smirnova I.I. 3D-modelirovaniye v geoinformatsionnoy sisteme [3D modeling in geographic information system]. Programmnyye produkty i sistemy, 2013, no. 1, pp. 122-125.

7. Tsvetkov V.Y. Tsifrovyye karty i tsifrovyye modeli [Digital maps and digital models]. Mezhdunarodnyy zhurnal prikladnykh i fundamental'nykh issledovaniy, 2016, no. 4-2, pp. 348-351. https://applied-research.ru/ru/article/view?id=8969 (accessed February 20, 2019).

8. Goralski, R., Ray, C. and Gold, C. Applications and benefits for the development of cartographic 3D visualization systems in support of maritime safety. TransNav-International Journal on Marine Navigation and Safety of Sea Transportation, 5, 2011, pp.423-431.

9. Haasea K., Kocha R. Extension of sea charts for 3-d visualization, 5th International 3D GeoInfo Conference, November 3-4, 2010, Berlin, Germany, pp. 125-128. https://www.isprs.org/proceedings/XXXVIII/4-W15/Paper_ISPRS/Poster/9_3DGeoInfo2010_124_Haase_Extension_of_Seecharts.pdf(January 14, 2019).

10. Hosgetts L. Poole Harbour's navigational safety goes 3D, February 28, 2013. https://www.pbo.co.uk/news/poole-harbours-navigational-safety-goes-3d-3556 (February 4, 2019).

11. Morgère, J.-C. Mobile augmented reality system for maritime navigation. Ph.D diss., Lorient, 2015. http://www.theses.fr/2015LORIS365. pdf (accessed February 4, 2019).

12. Porathe, T. Visualizing the Decision Space of a Ship's Maneuverability in a Real-Time 3-D Nautical Chart. In Visualisation and the Common 
Operational Picture, (pp. 23-1 - 23-10). Meeting Proceedings RTOMP-IST-043, Paper 23. 2005, Neuilly-sur-Seine, France: RTO. https:// www.researchgate.net/publication/228730056_Visualizing_the_Decision_Space_of_a_Ship's_Maneuverability_in_a_Real-Time_3-D_ Nautical_Chart (accessed January 14, 2019).

13. Porathe, T. 3-D nautical charts and safe navigation. Ph.D., Gävle, Sweden, 2006. http://www.diva-portal.org/smash/get/diva2:120506/FULLTEXT01.pdfAn (accessed February 4, 2019).

14. Ray C., Goralski R., Claramunt C. and Gold, C. Real-time 3D monitoring of marine navigation. Information Fusion and Geographic Information Systems, Published in: Lecture Notes in Geoinformation and Cartography, 2011, Berlin, pp. 161-175.

15. C-Vuß 3D VTS - Milford Haven / demonstration video. https://vimeo. com/38025373 (accessed November 11, 2018).

16. C-Vu ${ }^{\circledR} 3 \mathrm{D}$ VTS - Southampton / demonstration video. https://vimeo. com/45640579 (accessed November 7, 2018).

17. Demonstration of the GeoVS Maritime Domain Awareness (MDA) real-time 3D VTS display technology from SRT Marine System Solutions / demonstration video. https://vimeo.com/101169448 (accessed November 7, 2018).

18. Pilotage out of Poole / demonstration video https://vimeo.com/59227199 (accessed November 7, 2018).

19. New 3D vessel traffic management system enhances safety at Poole Harbour, February 25, 2013. http://shipmanagementinternational.com/ new-3d-vessel-traffic-management-system-enhances-safety-at-pooleharbour/ (accessed November 7, 2018).

20. Transas Marine, Navi - Sailor 4000 (ver. 6.42), Navigational Bridge, Transas Marine GB, Ltd., 2007.

\section{ДАННЫЕ ОБ АВТОРЕ}

Прохоренков Андрей Александрович, доцент кафедры «Судоходства на внутренних водных путях», кандидат технических наук Федеральное государственное бюджетное образовательное учреждение высшего образования «Государственный 
университет морского и речного флота имени адмирала С.О. Макарова»

ул. Двинская 5/7, г. Санкт-Петербург, 198035, Российская Федерачия

a.a.prokhorenkov@mail.ru

\section{DATA ABOUT THE AUTHOR}

Prokhorenkov Andrei Aleksandrovich, Associate Professor of chair «Inland Waterway Navigation», Candidate of Engineering Sciences Admiral Makarov State University of Maritime and Inland Shipping 5/7, Dvinskaya St., Saint-Petersburg, 198035, Russian Federation a.a.prokhorenkov@mail.ru

ORCID: 0000-0002-7310-9555 